\title{
CO-DIGESTÃo ANAERÓBIA dE SUBSTÂNCIAS SURFACTANTES, ÓLEO E LODO DE ESGOTO
}

\section{ANAEROBIC CODIGESTION OF SURFACTANTS SUBSTANCES, OIL AND SLUDGE OF SEWAGE}

\section{Maria José Comandante Costa}

Química Industrial e Mestra em Saneamento Ambiental. Professora da rede Pública Ensino do Estado da Paraíba

\section{José TaVARES DE SOUSA}

Doutor em Hidráulica e Saneamento, USP. Professor do Departamento de Química, Curso em Engenharia Sanitária e Ambiental - Universidade Estadual da Paraíba (UEPB)

\section{VALDERI DUARTE LEITE}

Doutor em Hidráulica e Saneamento, USP. Professor do Departamento de Química, Curso em Engenharia Sanitária e Ambiental - Universidade Estadual da Paraíba (UEPB)

\section{WILTON DA SILVA LOPES}

Doutor em Química. Professor Departamento de Química, Curso em Engenharia Sanitária e Ambiental - Universidade Estadual da Paraíba (UEPB)

\section{KeLIana Dantas Santos}

Química Industrial e Mestranda em Saneamento Ambiental do PRODEMA- UFPB/UEPB

Recebido: 27/10/06 Aceito: 31/10/07

\section{RESUMO}

O objetivo deste trabalho foi investigar a viabilidade de se tratar conjuntamente substâncias surfactantes, óleo mineral e lodo de esgoto sanitário. Para todos os tratamentos foram analisadas as concentraçóes de matéria orgânica (DQO) afluente e efluente. $\mathrm{O}$ sistema experimental foi monitorado durante 150 dias e diariamente eram realizadas quantificações do volume e da composição do biogás produzido. Foram constatadas remoçóes de DQO filtrada média de $82 \%$ aos 18 dias, e para DQO bruta em torno de $76 \%$ para os seis tratamentos aos 100 dias de operação. A produção de metano observada durante o período experimental demonstrou que as diferentes concentrações de surfactantes presentes no sistema não se mostraram tóxicas o suficiente para inibir as bactérias metanogênicas.

PALAVRAS CHAVE: Surfactante, digestão anaeróbia, óleo mineral.

\section{INTRODUÇÃO}

Os avanços da tecnologia e dos processos industriais têm contribuido com o surgimento de novos compostos químicos sintéticos de estruturas moleculares e seqüências químicas de difícil degradação por microrganismos, geralmente, resistentes à biodegradação, os chamados xenobióticos. Alguns desses compostos resistem à biodegradação, outros não, são metabolizados completamente, acumulando-se no ambiente, podendo ser considerados recalcitrantes e outros são polimerizados (Bitton, 1999).

A indústria de petróleo vem causando uma série de impactos ambientais, como por exemplo, derivados de petróleo usados para fazer asfalto, combustíveis e lubrificantes, surfactantes, produtos usados em detergentes e material de limpeza, plásticos com múltiplas utilidades, pesticidas, pneus, perfumes, aromatizantes, corantes e pigmentos. Existem também compostos xenobióticos naturais como, por exemplo, substâncias húmicas e ligninas bem como compostos halogenados encontrados, geralmente em ambiente marinho. 
Os surfactantes são moléculas constituídas de uma parte hidrofóbica e outra hidrofílica. A parte apolar da molécula é freqüentemente uma cadeia hidrocarbonada enquanto a parte polar pode ser iônica (aniônica ou catiônica), não-iônica ou anfotérica. A maioria dos surfactantes disponível comercialmente é sintetizada a partir de derivados de petróleo (Nitschke \& Pastore, 2002).

A partir da metade do século passado, começou a produção dos alquilbenzenos ramificados (ABS), resultantes da sulfonação do propileno tetramérico e do benzeno, apresentando ótimo poder de limpeza. Estes compostos por conter cadeia ramificada apresentaram problemas como baixa biodegradabilidade, além da geração de grandes camadas de espuma nas superfícies aquáticas, tendo a indústria no início da década seguinte desenvolvido os alquilbezenos sulfonados lineares (LAS) que, têm o mesmo poder de limpeza dos alquilbezenos ramificados e têm uma maior biodegradabilidade. Hoje, o LAS é o tensoativo sintético mais produzido mundialmente, sendo empregado na produção da maioria dos detergentes, substituindo o ABS, sendo que, os surfactantes estão entre os principais poluentes encontrados nos esgotos (Metcalf \& Eddy, 2003)

Os compostos que constituem a base dos detergentes são: agente umedecedor, que são os tensoativos; agente complexante e uma base para neutralizar os ácidos presentes na solução. Os tensoativos são os chamados surfactantes, compostos orgânicos que diminuem a tensão superficial da água, propiciando a limpeza de superfícies e também emulsionam óleos formando suspensões. Os tensoativos são usados por diversos setores da indústria, principalmente no setor de detergentes, de indústria têxtil, indústria alimentar, tinturarias, cosmética, manufatura de papel, mineração, dentre outros.

Por outro lado, a utilização abusiva dos tensoativos causa para o meio ambiente prejuízos tais como: inibição ou paralisação da depuração natural ou artificial devido à formação de espumas estáveis, formadas com a presença de tensoativos aniônicos; alteração da condução de oxigênio através das membranas dos organismos aquáticos; eutrofização das águas superficiais devido à presença de fosfatos na composição dos tensoativos e alguns detergentes contém compostos com boro, aumen- tando ao longo do tempo a quantidade dessa substância nas águas superficiais e subterrâneas (Costa, 2006 ).

Os consórcios de microrganismos responsáveis pelos processos aeróbios e anaeróbios, assim como os estudos da fisiologia dos microrganismos têm importância para o saneamento ambiental, principalmente os que degradam substâncias tóxicas. Moléculas orgânicas xenobióticas como os alquilbenzenos sulfonados lineares (LAS) e ramificados (ABS) podem sofrer biodegradação pelos processos biológicos aeróbios e anaeróbios, apesar do passo limitante para a degradação microbiana que é a separação do radical alquila do anel benzeno sulfonado, sendo este anel, degradado posteriormente a dióxido de carbono, água e sulfato (Vazoller, 2004).

Além dos detergentes e material de limpeza de utilização doméstica, também os lava-jatos geram uma considerável quantidade de água residuária, contendo detergentes, óleo e outros derivados de petróleo incluindo hidrocarbonetos aromáticos, sobretudo, benzeno, tolueno, etilbenzeno e xilenos (BTEX), além de algumas substâncias que são empregadas na limpeza de veículos. Estes poluentes são lançados continuamente nos sistemas de esgotamento sanitário das cidades, uma vez que a maioria dos lava-jatos não faz nenhum tratamento dos seus efluentes. Alguns adotam apenas um sistema de separação física do óleo presente na água, que são as caixas de areia, funcionando estas como um paliativo para minimizar os impactos causados ao meio ambiente por este tipo de lançamento, uma vez que a parte solúvel do óleo não fica retida na caixa de areia, além do fato de que a areia impregnada de óleo torna-se um passivo ambiental (Costa, 2006). O óleo e outros derivados de petróleo possuem substâncias recalcitrantes para o meio ambiente podendo causar vários danos ecológicos e também afetar a saúde dos seres humanos. Portanto, o objetivo deste trabalho foi estudar o processo de co-digestão anaeróbia de substâncias surfactantes, óleo mineral e lodo anaeróbio de esgoto sanitário.

\section{MATERIAL E MÉTODOS}

O sistema experimental foi construído, instalado e monitorado na Estação Experimental de Tratamento Biológico de Esgoto Sanitário (EXTRABES), localiza- da em área pertencente à Companhia de Águas e Esgotos do Estado da Paraíba (CAGEPA), no município de Campina Grande - PB, com coordenadas geográficas de $07^{\circ} 13^{\prime} \mathrm{S}$ e $35^{\circ} 52^{\prime} \mathrm{W}$ e altitude de $550 \mathrm{~m}$ acima do nível do mar.

Para a realização do trabalho experimental, foram instalados e monitorados reatores de batelada com capacidade unitária de 1,10 L, constituindo 6 tratamentos com 4 repetições, compreendendo 26 reatores (Figura 1). O monitoramento ocorreu durante 150 dias e o experimento foi conduzido em temperatura ambiente que variou de 28 a $32^{\circ} \mathrm{C}$.

Os reatores foram alimentados com resíduos preparados quantitativamente com lodo de esgoto sanitário advindo de reator UASB, água destilada, detergente, xampu para carros, óleo lubrificante e nutrientes. O xampu apresentava a seguinte composição: alquil benzeno sulfonato de sódio, coadjuvantes, tamponantes, corantes e branqueador. Na Tabela 1 são apresentados os dados das proporções dos diversos tipos de resíduos e as respectivas concentraçōes.

Cada reator foi inoculado com $200 \mathrm{~mL}$ de lodo e acrescentou-se a estes $600 \mathrm{~mL}$ dos respectivos substratos para cada tratamento. Os $\mathrm{pHs}$ dos substratos foram corrigidos com uma solução de hidróxido de sódio para aproximadamente 7. A solução de nutrientes utilizada foi o meio mineral Bushnell Hass Broth $\left(\mathrm{MgSO}_{4}-0,2 \mathrm{~g} / \mathrm{L}\right.$; $\mathrm{CaCl}_{2}-0,02 \mathrm{~g} / \mathrm{L} ; \mathrm{KH}_{2} \mathrm{PO}_{4}-1 \mathrm{~g} / \mathrm{L}$; $\left.\mathrm{NH}_{4} \mathrm{NO}_{3}-1 \mathrm{~g} / \mathrm{L} ; \mathrm{FeCl}_{3}-0,05 \mathrm{~g} / \mathrm{L}\right)$.

$\mathrm{O}$ inóculo utilizado, para cada reator, foi $200 \mathrm{~mL}$ de lodo anaeróbio proveniente de reator UASB. A este foram adicionados os respectivos substratos; a mistura foi agitada por dez minutos e deixada em repouso por um período de 20 horas. As análises iniciais foram feitas com o sobrenadante retirado dos reatores após o período de sedimentação. Em seguida, foi colocado, novamente, em cada reator $600 \mathrm{~mL}$ dos seus respectivos substratos para que então fossem vedados e monitorados. Ao serem abertas, no final da etapa, as análises foram feitas com o sobrenadante retirado de cada reator.

Os reatores foram vedados com tampas com uma abertura forrada com borracha, para se proceder à retirada de biogás com uma seringa. Após cada retirada de biogás, a abertura era vedada com cola de silicone. A cada vinte 


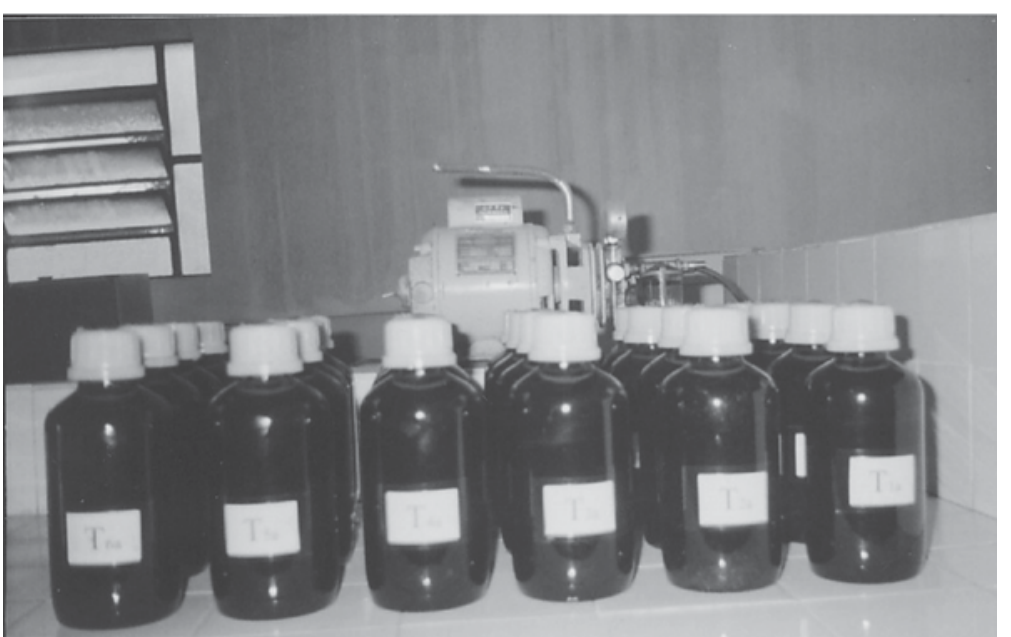

Figura I- Reatores utilizados no experimento

Tabela I - Quantidades das substâncias utilizadas na preparação dos substratos

\begin{tabular}{ccccc}
\hline Tratamentos & $\begin{array}{c}\text { Óleo } \\
(\mathrm{g})\end{array}$ & $\begin{array}{c}\text { Detergente } \\
(\mathrm{g})\end{array}$ & $\begin{array}{c}\text { Água } \\
(\mathrm{mL})\end{array}$ & $\begin{array}{c}\text { Fonte de Nutrientes } \\
(\mathrm{mL})\end{array}$ \\
\hline T1 & - & - & 900 & 100 (solução de nutrientes) \\
T2 & - & 1,5 & 900 & 100 (solução de nutrientes) \\
T3 & 0,03 & 1,0 & 900 & 100 (solução de nutrientes) \\
T4 & 0,03 & 3,0 & 900 & 100 (solução de nutrientes) \\
T5 & 0,06 & 1,5 & 900 & 100 (solução de nutrientes) \\
T6 & 0,03 & 1,5 & 900 & 100 (esgoto bruto) \\
\hline
\end{tabular}

Onde T: Tratamento

e quatro horas, após os reatores serem agitados por trinta segundos, foram medidos os volumes de biogás produzidos, utilizando-se para isto um manômetro, e através de cromatografia gasosa, foram determinadas as composiçōes da mistura gasosa, os percentuais de metano, dióxido de carbono e nitrogênio.

Para se calcular o volume de metano, foram utilizadas as seguintes equações:

$\mathrm{P}_{\mathrm{t}}=\mathrm{P}_{0}+\frac{\mathrm{h}}{10,33}$

$\mathrm{d}=\frac{\mathrm{P}_{\mathrm{t}} \cdot \mathrm{M}}{\mathrm{R} \cdot \mathrm{T}}$

$\mathrm{P}_{\mathrm{t}}$ : Pressão total (atm);

$\mathrm{P}_{0}^{\mathrm{t}}$ : Pressão ambiente (atm);

$\mathrm{h}$ : Deslocamento da coluna de água (m);

$\mathrm{d}$ : Densidade $\left(\mathrm{g} / \mathrm{cm}^{3}\right)$;

$\mathrm{M}$ : Massa molar $(\mathrm{g} / \mathrm{mol})$;

$\mathrm{R}: 0,082$ (atm / k . mol);

$\mathrm{T}:$ Temperatura $(\mathrm{k})$

A massa de gás metano poderá ser determinada, empregando-se a Equação 3.
Onde:

C : Concentração da DQO final (mg. $\left.\mathrm{L}^{-1}\right) ; \mathrm{C}_{0}$ : Concentração DQO inicial (mg. $\left.\mathrm{L}^{-1}\right)$;

$\mathrm{k}_{\mathrm{d}}$ : Constante de velocidade de descaimento $\left(\right.$ dia $\left.^{-1}\right)$;

$\mathrm{t}:$ Tempo (dia).

\section{APRESENTACÃO E DISCUSSÃO DOS RESULTADOS}

Na Tabela 2 são apresentados os valores da DQO bruta e da DQO filtra$\mathrm{da}$, afluentes e efluentes e as remoçōes, respectivamente, nos períodos de 100 e de 18 dias de operação dos reatores. Observa-se na Tabela 2 que durante os dezoito dias iniciais de operação foram suficientes para remover a DQO filtrada. O tratamento T4, o qual continha a maior concentração de detergente apresentou a maior remoção, que foi de $89 \%$, indicando que o detergente não inibiu o processo de biodegradação.

A eficiência de remoção de DQO aos 100 dias de experimento para os seis tratamentos manteve o mínimo de 67\% (tratamento T5) e máximo de $81 \%$ (tratamento T3). O tratamento T5 com o dobro da quantidade de óleo lubrificante apresentou uma maior dificuldade para a biodegradabilidade do seu substrato conforme se apresenta na Tabela 2. A fração do óleo solúvel em água que é formada por determinados compostos como os hidrocarbonetos monoaromáticos: benzeno, tolueno etilbenzeno, xilenos (BTEX) são compostos aromáticos que podem sofrer biodegradação por processos anaeróbios. Verificou-se nesta investigação que, ao final do tratamento, o óleo aparecia ainda no sobrenadante, indicando a sua difícil biodegradação.

Duarte et al (2005) operaram dois reatores anaeróbios horizontais de leito fixo com biomassa imobilizada tratando LAS com diferentes condiçôes nutricionais conseguiram durante o período experimental uma eficiência de remoção de cerca de $50 \%$.

\section{Produção de gás metano}

As Figuras 2 e 3 apresentam o comportamento do volume acumulado de metano, respectivamente, para a remoção da DQO filtrada para os dezoito dias iniciais e para a remoção da DQO bruta. Vale salientar que para cada tratamento, havia quatro repetições, 
Tabela 2 - DQO afluente e efluente do substrato bruto e filtrado, suas remoções nos períodos de 100 e 18 dias, respectivamente

\begin{tabular}{|c|c|c|c|c|c|c|}
\hline \multirow[t]{2}{*}{ Tratamentos } & \multicolumn{2}{|c|}{$\mathrm{DQO}\left(\mathrm{mgO}_{2} / \mathrm{L}\right)$} & \multirow{2}{*}{$\begin{array}{c}\text { Remoção } \\
\text { (\%) }\end{array}$} & \multicolumn{2}{|c|}{$\mathrm{DQO}_{\text {filtrada }}\left(\mathrm{mgO}_{2} / \mathrm{L}\right)$} & \multirow{2}{*}{$\begin{array}{c}\text { Remoçáo } \\
(\%)\end{array}$} \\
\hline & Afluente & Efluente & & Afluente & Efluente & \\
\hline $\mathrm{T} 1$ & 3550 & 692 & 80 & 62 & 58 & 06 \\
\hline T2 & 3490 & 704 & 80 & 354 & 47 & 86 \\
\hline T3 & 4212 & 800 & 1 & 293 & 83 & 72 \\
\hline T4 & 3851 & 883 & 77 & 703 & 72 & 89 \\
\hline T5 & 2407 & 788 & 67 & 400 & 74 & 81 \\
\hline T6 & 3129 & 776 & 75 & 482 & 84 & 82 \\
\hline
\end{tabular}

portanto, cada ponto plotado na curva apresentada nas Figuras 2 e 3 corresponde ao valor das médias de quatro medidas de gás metano, com coeficiente de variação menor que $8 \%$.

Observa-se na Figura 2 que desde o início, o tratamento T4, que continha uma maior quantidade de detergente (3 g) acumulou uma maior quantidade de metano, vindo em seguida os tratamentos T6, com $1,5 \mathrm{~g}$ de detergente, $0,03 \mathrm{~g}$ de óleo. Em seguida, o tratamento $\mathrm{T} 5$, com $1,5 \mathrm{~g}$ de detergente e 0,06 g de óleo, o tratamento T2 com $1,5 \mathrm{~g}$ de detergente, e a seguir o tratamento T3 com 1,0 g de detergente e $0,03 \mathrm{~g}$ de óleo. Finalmente, vem o tratamento $\mathrm{T} 1$ que, sem detergente e óleo, produziu a menor quantidade de metano.

A Figura 3 apresenta o volume acumulado de metano durante os 150 dias de operação dos reatores dos seis tratamentos. Observa-se que a produção de metano foi crescente até cerca dos 120 dias, sendo que, a partir deste tempo ocorreu a diminuição dessa produção.
Durante os 150 dias, o tratamento T4 foi o que produziu um maior volume de metano $(2978 \mathrm{~mL})$; em segundo lugar, o tratamento T6 que atingiu o percentual máximo aos 102 dias com $40,52 \%$ de metano e acumulou $2567 \mathrm{~mL}$ do gás; em terceiro lugar está o tratamento T5, que atingiu o percentual máximo aos 119 dias com $38,71 \%$ de metano e acumulou 2377 mL do gás; em quarto lugar está o tratamento T2, que atingiu o percentual máximo aos 106 dias com 40,74\% de metano e acumulou 2302 mL do gás; em quinto lugar está o tratamento T3 que atingiu o percentual máximo aos 98 dias com 40,63\% de metano e acumulou 2109 mL do gás; e finalmente, em sexto lugar o tratamento T1 que atingiu o percentual máximo aos 98 dias com $36,41 \%$ de metano e acumulou $1910 \mathrm{~mL}$ do gás.

O tratamento T6, no qual os nutrientes (meio mineral Bushnell Hass Broth) foram substituídos por esgoto bruto, apresentou a segunda maior produção de metano, indicando que neste tipo de tratamento esgoto bruto, pode substituir os nutrientes minerais.

A mistura de óleo mineral e detergente juntamente com $1 / 4$ do volume de lodo em cada reator proporcionou uma considerável quantidade e diversidade de microrganismos anaeróbios que favoreceu o processo de co-digestão, considerando-se que, inicialmente tem-se o consumo da DQO solúvel, posteriormente da particulada e a da DQO expressos em sólidos suspensos voláteis do próprio lodo à medida que vai sofrendo processo de hidrólise durante o período de incubação.

\section{Parâmetros ambientais}

$\mathrm{Na}$ Tabela 3 são apresentados os valores dos parâmetros químicos dos seis tratamentos para o período de 100 dias de operação dos reatores de batelada.

Observa-se na Tabela 3 que ocorreu um acréscimo dos AGVs e da alcalinidade total em todos os tratamentos. Quanto ao aumento dos AGVs, pode ser uma evidência de que a fermentação ácida dos sistemas de tratamento se sobressaiu em relação à fermentação metanogênica (van Haandel e Lettinga, 1994). Tratar LAS por processo anaeróbio é muito difícil, ocorre inibição das bactérias metanogênicas (Wagner e Shink, 1987; Fedrele e Shwab, 1992). A degradação de surfactante tipo LAS foi estudada em dois estágios de sistemas anaeróbios onde o reator continha Pseudomonas aeruginosa. Os resultados mostraram que os surfactantes só foram destruídos no reator acidogênico, enquanto que no reator metanogênico não ocorreu degradação, eventualmente havia uma inibição devido a uma

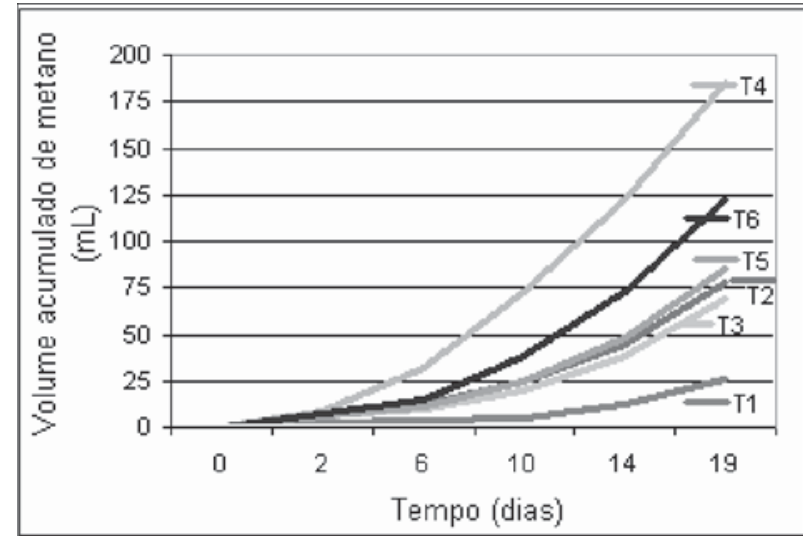

Figura 2 - Volume acumulado de metano para a remoção da DQO filtrada

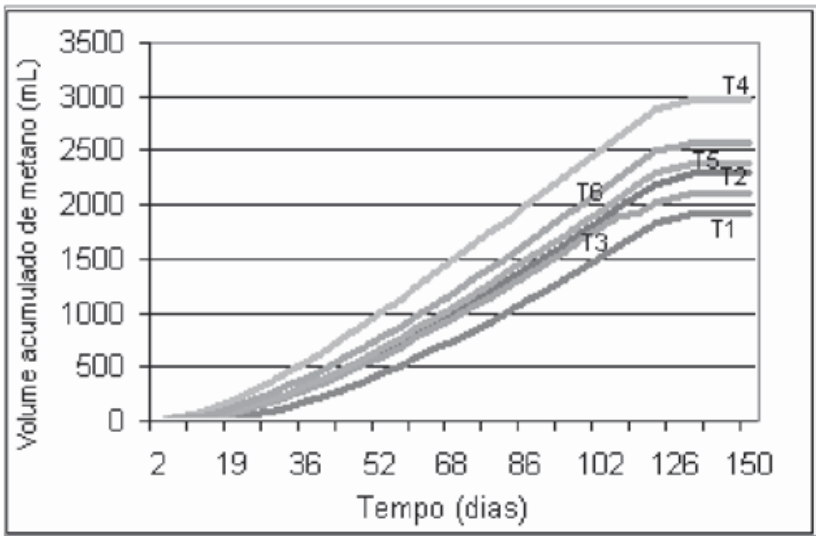

Figura 3 - Volume acumulado de metano durante os 150 dias de operação 
acumulação de LAS no lodo anaeróbio (Almendariz et al, 2000).

\section{Metano teórico e medido}

O volume teórico de metano e o volume medido para os primeiros dezoito dias de operação dos reatores nos seis tratamentos são apresentados na Tabela 4. Observa-se na Tabela que o material filtrado, provavelmente, detergentes contendo considerada fração de alquilbenzenos sulfonados lineares (LAS) e sólidos dissolvidos oriundo do lodo anaeróbio, foi parcialmente consumido durante os dezoito dias iniciais. Substâncias como os LAS e ramificados (BAS) podem ser degradados por processos biológicos, no entanto, a degradação desses detergentes é complexa. O primeiro passo na degradação por via biológica é a dessulfonação do anel aromático, seguida pela oxidação da cadeia alquílica (Vazoller, 2004).

A degradação de detergente só se completa com e a ruptura do radical alquila e a abertura do anel benzeno. Apesar de não ser bem conhecidas as etapas da biodegradação, as bactérias anaeróbias são capazes de utilizarem os alquilbenzenos sulfonados lineares como fonte de energia de carbono e de enxofre (Cook et al, 1999 apud Duarte et al, 2005).

Nos dez primeiros dias de operação dos reatores não ocorreu produção de metano. Entretanto após esse período de adaptação, observou-se a presença de metano no biogás analisado, sobretudo nos reatores do tratamento T3 que continham menos concentração de surfactante. No entanto, o tratamento T4 contendo maior concentração de surfactante, no final do experimento atingiu a maior produção de metano, seguido do tratamento T6, conforme Tabela 4.

Os dados relativos à DQO de metano e o gás medido, observados na Tabela 4, são coerentes. Os maiores valores de metano observados na DQO filtrada teórica devem-se, provavelmente, a sulfetogênese. Possivelmente, no lodo havia população de bactérias redutoras de sulfato acetrotróficas suficientes para consumir acetato durante o processo de sulfetogênese.

\section{Constantes cinéticas de decaimento da DQO}

Os estudos sobre a biodegradação de material orgânico em sistemas

Tabela 3 - Parâmetros químicos afluentes e efluentes dos tratamentos para o período de 100 dias de operação dos reatores

\begin{tabular}{ccccccc}
\hline Tratamentos & \multicolumn{2}{c}{$\mathrm{pH}$} & \multicolumn{5}{c}{$\begin{array}{c}\text { Alcalinidade Total } \\
\left(\mathrm{mgCaCO}_{3} / \mathrm{L}\right)\end{array}$} & AGV(mgHAc./L) \\
\hline & Afluente & Efluente & Afluente & Efluente & Afluente & Efluente \\
T1 & 7,2 & 7,3 & 203,9 & 402,6 & 13,8 & 50,9 \\
$\mathrm{~T} 2$ & 7,6 & 7,5 & 214,2 & 419,7 & 18,6 & 31,4 \\
$\mathrm{~T} 3$ & 7,4 & 7,1 & 232,8 & 401,4 & 39,1 & 63,2 \\
$\mathrm{~T} 4$ & 7,4 & 7,5 & 263,9 & 442,1 & 52,4 & 63,9 \\
T5 & 7,3 & 7,8 & 209,1 & 382,6 & 37,9 & 75,8 \\
T6 & 7,4 & 7,3 & 222,5 & 393,1 & 31,6 & 72,9 \\
\hline
\end{tabular}

Tabela 4 - DQO filtrada removida, volume teórico de metano da DQO filtrada e volume de metano medido durante os dezoito primeiros dias de operação dos reatores

\begin{tabular}{|c|c|c|c|c|c|}
\hline \multirow[t]{2}{*}{ Tratamentos } & \multicolumn{2}{|c|}{$\begin{array}{l}\mathrm{DQO}_{\text {filtrada }} \\
\left(\mathrm{mg} \cdot \mathrm{L}^{-1}\right)\end{array}$} & \multirow[t]{2}{*}{$\begin{array}{l}\mathrm{DQO}_{\text {removida }} \\
(\mathrm{mg})\end{array}$} & \multirow[t]{2}{*}{$\begin{array}{l}\mathrm{CH}_{4 \text { DQO filtrada }} \\
(\mathrm{mL})\end{array}$} & \multirow[t]{2}{*}{$\begin{array}{l}\mathrm{CH}_{4} \text { medido } \\
\quad(\mathrm{mL})\end{array}$} \\
\hline & Afluente & Efluente & & & \\
\hline $\mathrm{T} 1$ & 62 & 58 & 3,2 & - & - \\
\hline $\mathrm{T} 2$ & 354 & 47 & 245 & 85 & 53 \\
\hline $\mathrm{T} 3$ & 293 & 83 & 168 & 59 & 48 \\
\hline $\mathrm{T} 4$ & 703 & 72 & 505 & 177 & 112 \\
\hline $\mathrm{T} 5$ & 400 & 74 & 260 & 91 & 60 \\
\hline T6 & 482 & 84 & 318 & 111 & 84 \\
\hline
\end{tabular}

biológicos têm sido realizados levando-se em consideração duas fases: uma lenta, que é o período necessário para adaptação e inicio da multiplicação da massa bacteriana, além de uma fase de decomposição rápida, cujo crescimento bacteriano é máximo. Dessa forma, a taxa de biodegradação do substrato pode ser descrita por modelos exponenciais (Leite et al, 2001).

Diversos autores têm descrito o comportamento da estabilização biológica da matéria orgânica obedecendo à cinética de $1^{\mathrm{a}}$ ordem, tomando-se como base à biodegradabilidade do substrato a pH e temperatura constantes, conforme descrito na Equação 6 (Sanders et al, 2000; Lopes et al, 2004).

A constante de decaimento $(\mathrm{kd})$ da equação 6 , indica a velocidade com que o material orgânico é degradado no interior do reator biológico, quanto maior o valor da constante mais rápido o material orgânico é degradado e, conseqüentemente, melhor é o desempenho do processo.

A Tabela 5 apresenta os valores das constantes de decaimento para a DQO filtrada, a DQO bruta e a DQO do lodo obtidos durante a operação dos reatores.

Analisando os dados apresentados na Tabela 5 constata-se que os valores das constantes de decaimento para a DQO filtrada apresentaram valores maiores que os encontrados para DQO bruta e para a DQO do lodo. O que indica que a DQO filtrada apresentou uma velocidade de remoção maior que as outras duas frações. Este fato pode estar relacionado com as características do material a ser degradado, sendo a DQO filtrada rapidamente digerida, vindo em seguida a DQO bruta e a DQO do lodo, respectivamente.

Os valores da constante de decaimento encontrados para DQO filtrada situaram-se próximos de $0,1 \mathrm{dia}^{-1}$, exceção feita ao tratamento T1 no qual o substrato foi preparado apenas com água e solução de nutrientes o que forneceu uma DQO de apenas $62 \mathrm{mg} \cdot \mathrm{l}^{-1}$. Estes valores estão próximos dos valores encontrados na literatura para esgotos domésticos tratados em sistemas anaeróbios (Metcalf \& Eddy, 2003 ).

A remoção de DQO do lodo apresentou constantes de decaimento na 
ordem de 0,0027 $\mathrm{dia}^{-1}$, estes valores encontram-se próximos dos encontrados por diversos autores quando estudavam a biodegradação de resíduos sólidos em sistemas anaeróbios (Barzacconi et al, 1997; Leite e Povinelli, 1999; Lopes et al, 2004).

Como se observa na Tabela 5 , a constante de decaimento da DQO do lodo manteve-se próximas em todos os tratamentos, sendo o tratamento $\mathrm{T} 1$ o que mais removeu a DQO permanecendo no sistema $61,9 \%$ da DQO inicial, o que pode ser justificado pela ausência dos outros substratos (detergente e óleo), o que possivelmente fez com que houvesse uma maior degradação do próprio lodo. $\mathrm{O}$ tratamento T6 foi o que menos removeu DQO, permanecendo no sistema $70,8 \%$ da DQO inicial.

Nas Figuras 4 e 5 são apresentadas respectivamente, a DQO filtrada a DQO bruta, remanescentes nos reatores após o término do tratamento.

Como se pode observar na Figura 4, o tratamento $\mathrm{T} 1$, que não continha óleo e detergente, praticamente, não apresentou remoçáo de DQO, permanecendo no sistema após o término do tratamento $93,5 \%$ da DQO inicial. Para o tratamento T3, permaneceu no sistema $28,4 \%$ da DQO inicial; para o tratamento $\mathrm{T} 5,18,5 \%$, para o tratamento T6, $17,4 \%$, para o tratamento T2, que não continha óleo, permaneceu no sistema apenas $13,3 \%$ da DQO inicial e no tratamento T4, cuja quantidade de detergente foi a maior, permaneceu no sistema a menor quantidade da DQO inicial dentre todos os tratamentos, $10,2 \%$.

Observa-se na Figura 5 que o tratamento T3, que continha uma menor quantidade de detergente, foi

Tabela 5 - Constantes de decaimento da DQO

\begin{tabular}{cccc}
\hline Tratamentos & $\mathrm{DQO}_{\text {filtrada }}\left(\mathrm{kd} \cdot \mathrm{dia}^{-1}\right)$ & $\mathrm{DQO}_{\text {bruta }}\left(\mathrm{kd} \cdot \mathrm{dia}^{-1}\right)$ & $\mathrm{DQO}_{\text {lodo }}\left(\mathrm{kd} \cdot \mathrm{dia}^{-1}\right)$ \\
\hline $\mathrm{T} 1$ & 0,0037 & 0,016 & 0,0032 \\
$\mathrm{~T} 2$ & 0,1121 & 0,016 & 0,0027 \\
$\mathrm{~T} 3$ & 0,0700 & 0,016 & 0,0024 \\
$\mathrm{~T} 4$ & 0,1265 & 0,015 & 0,0029 \\
T5 & 0,0937 & 0,011 & 0,0028 \\
T6 & 0,0970 & 0,013 & 0,0023 \\
\hline
\end{tabular}

o que apresentou a maior remoção de DQO, restando no sistema $19 \%$ da DQO de entrada. O tratamento T5, cujo substrato continha uma maior quantidade de óleo, apresentou uma menor remoção, permanecendo no sistema $32,7 \%$ da DQO inicial. No tratamento T6 restaram 24,8\% da DQO inicial, no tratamento T4, $22,9 \%$, no tratamento T2, 20,2 \% e no tratamento $\mathrm{T} 1,19,5 \%$.

\section{CONCLUSÕES}

A possibilidade de tratamento biológico de resíduos contendo surfactante, óleo mineral e lodo de esgoto sanitário carece de mais investigação. Neste estudo foi utilizada a tecnologia de reator de batelada e, nas condiçóes de operação do mesmo, pode-se concluir que:

O tratamento anaeróbio para águas residuárias contendo óleo mineral, alquilbenzenos lineares sulfonados em concentrações variando de 1 a 3 g. $\mathrm{L}^{-1}$ juntamente com lodo anaeróbio com 26,7 g de sólidos suspensos voláteis por litro de lodo é aplicável, ficando evidente a biodegradação desses materiais, apesar do tempo relativamente longo para o processo de biodegradação.
Com tempo de experimentação variando de 98 a 150 dias, a eficiência de remoção da DQO filtrada variou de 47 a $84 \%$, enquanto que para a DQO bruta a eficiência de remoção manteve-se entre 67 a $81 \%$. Foi observado que quanto maior a quantidade de surfactante utilizada na mistura do material submetido co-digestão maior a DQO solúvel dos substratos.

A presença de óleo em pequenas concentrações $(0,03$ a $0,06 \mathrm{~g} / \mathrm{L})$ não inibiu o tratamento biológico, mas o seu tratamento mostrou-se complexo, devido a sua baixa densidade, insolubilidade na água e capacidade de agregar-se ao meio.

A produção de metano observada durante o período experimental demonstrou que as diferentes concentraçóes de surfactantes presentes no sistema não se mostraram tóxicas o suficiente para inibir as bactérias metanogênicas.

\section{AGRADECIMENTO}

Os autores agradecem ao CTHidro, ao CNPq, à Companhia de Águas e Es-gotos da Paraíba-CAGEPA, a EXTRABES e ao Programa de Pesquisa em Saneamento Básico - PROSAB.

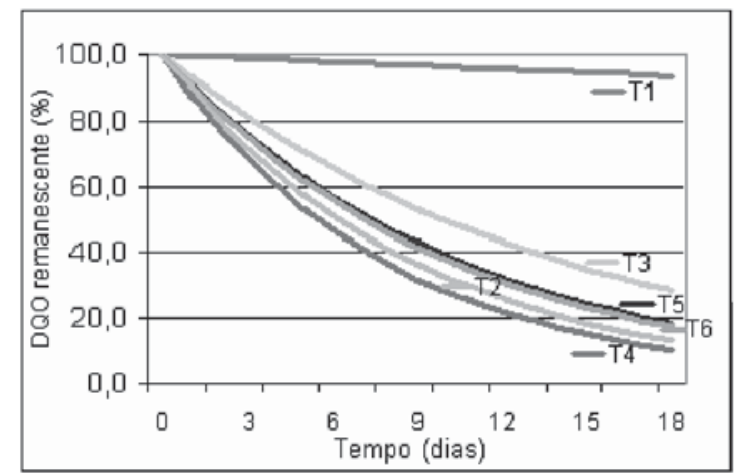

Figura 4 - DQO filtrada remanescente nos reatores após 18 dias de tratamento

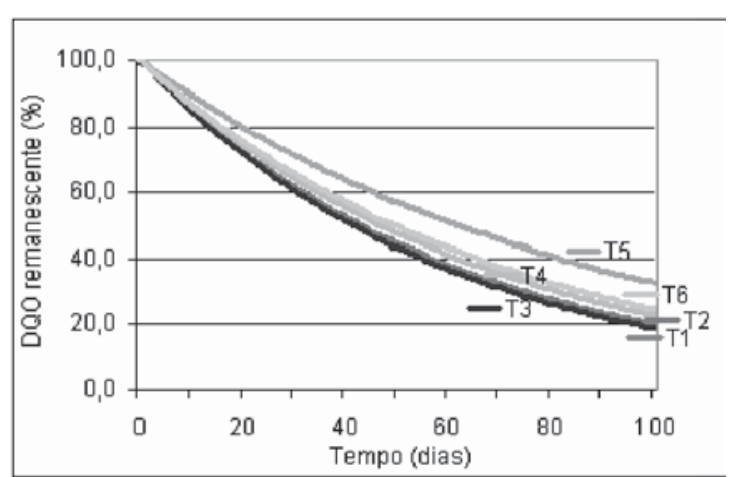

Figura 5 - DQO bruta remanescente nos reatores após 100 dias de tratamento 


\section{REFERÊNCIAS}

ALMENDARIZ, F. J. et al. Degradation alkylbenzene sulphonate (LAS) in an acidogenic reactor bioaugmented with a pseudomonas aeruginosa (M113) strain. In: VI OFICINA E SEMINÁRIO LATINO-AMERICANO DE DIGESTÃO ANAERÓBIO.2000, Recife. Anais.. v.1,p.278-284. 2000.

APHA. Standard Methods for the examination of water and wastewater. $15 \mathrm{ed}$. Washington, D.C. Amercan Health Association, 1134 p, 1995.

BITTON, G. Wastewater microbiology. 2 ed. USA, Ed. Wiley-Liss, 578p. 1999.

BORZACCONI, L.; LÓPEZL, I.; ANIDO, C. Hydrolysis constant and vfa inhibition in acidogenic phase of msw anaerobic degradation. Water Science Technology, v.36, n.6-7, p. 497-484, 1997.

COSTA, M.J.C.Tratamento biológico de efluente de lava-jatos. Dissertação de Mestrado. PRODEMA/Universidade Federal da Paraíba/ Universidade Estadual da Paraíba.108p, 2006.

DUARTE, I.C.S.; AGUILA, N.K.S.D., VARESCHE M.B.A. Tratamento de linear alquilbenzeno sulfonato em reator anaeróbio horizontal de leito fixo. In: SEMINÁRIO DE PROJETO TEMÁTICO, 2005, São Carlos. Anais...p.30-39, 2005.

FEDERLE, T. W.; SCHWAB, B.S. Mineralization of surfactants in anaerobic sediments of laundromat watewater pond, Water Research, v.26, p.123-127, 1992

LEITE, V. D.; LOPES, W. S.; PRASAD, S., Bioestabilização anaeróbia de resíduos sólidos or gânicos em reatores de batelada. Revista Brasileira de Engenharia Agrícola e Ambiental. v.5, n. 1, p. 119-123, 2001
LEITE, V. D.; POVINELLI P, J. - Comportamento dos sólidos totais no processo de digestão anaeróbia de resíduos sólidos urbanos e industriais. Revista Brasileira de Engenharia Agrícola e Ambiental. v. 3, n. 2, p. 229-232, 1999.

LOPES, W. S.; LEITE, V.D.; PRASAD, S. Influence of inoculum on performance of anaerobic reactors for treating municipal solid waste. Bioresource Technology, v. 94, p. 261-266, 2004.

NITSCHKE, M., PASTORE,G.M. Biossurfactantes: propriedades e aplicação. Química Nova, v. 25, n.5, p.772-776, 2002.

METCALF \& EDDY. Inc. Wastewater Engineering Treatment and Reuse. 4. ed. NewYork, Ed. McGraw-Hill Book, 1815p, 2003.

SANDERS, M. et al. Anaerobic hydrolysis of particulate substrates. Water Science and Technology, v. 41, n. 3, p. 17-24, 2000.

VAN HAANDEL, A. C. ; LETTINGA G. Tratamento anaeróbio de esgotos - um manual para regiōes de clima quente. 1994.

VAZOLLER, R. F. Biodiversidade: Perspectivas e oportunidades tecnológicas. Microbiologia e Saneamento Ambiental. Disponível em: <http://www. ddt.fat..gov.br/publicscoes/padct/bio/cap $9 / 3$ Acesso em: 3 dez.. 2004.

WAGNER, S; SHINK, B. Anaerobic degradation of nonionic and surfactants in enrichment cultures and fixed-bed reactors, Water Research, v.21, p.615-623, 1987.
Endereço para correspondência:

Maria José Comandante Costa

Escola Argemiro de Figueiredo

Av. Elpídio de Almeida, S/No

Bairro do Catolé

58 $104-693$ Campina Grande-

Paraíba - Paraíba - Brasil 